\title{
Sobre mitologias ancestrais e contemporâneas
}

\author{
Sílvio Anaz' \\ http://orcid.org/0000-0002-4851-4903 \\ I - Escola de Comunicações e Artes \\ da Universidade de São Paulo . \\ São Paulo (SP). Brasil.
}

Resumo: Este artigo discute a tipificação de sagas narrativas criadas a partir do século 20 como mitologias contemporâneas. A fundamentação teórica revê os conceitos de mito em Eliade, Cassirer, Jung e Durand para entender até que ponto eles se aplicam ao que se tem comumente chamado de mitologia contemporânea ou moderna, como no caso da saga transmídia Guerra nas Estrelas. Metodologicamente, faz-se um estudo comparativo da saga com elementos de mitologias ancestrais. A conclusão mostra que, apesar de terem pontos de convergência, a chamada mitologia contemporânea diverge da ancestral em relação a aspectos e alcance de suas funções psicológica e social e quanto à crença.

Palavras-chave: mito; mitologia; processos criativos; narrativas; Guerra nas Estrelas.

Abstract: On ancestral and contemporary mythologies - This essay discusses the classification of narratives created from the 20th Century as contemporary mythologies. The theory reviews the concepts about myth in Eliade, Cassirer, Jung, and Durand to understand how these concepts apply to narratives that have been considered contemporary or modern mythologies, such as Star Wars. Methodologically a comparative study is developed between Star Wars and elements from ancestral mythologies. The conclusion shows that, even though there are points of convergence, the referred contemporary mythology diverges from ancestral mythology in regard to the outreach of its psychological and social function as such about the creed.

Keywords: myth; mythology; creative processes; narratives; Star Wars. 


\section{Introdução}

A reflexão e a análise desenvolvidas neste artigo são motivadas pela frequente tipificação de algumas narrativas ficcionais criadas a partir do século XX como mitologias contemporâneas ou mitologias modernas, como acontece com Guerra nas Estrelas, assim classificada por seu criador e produtores (MOYERS, LUCAS, 1999; DISNEY, 2020), jornalistas (D'ANCONA, 2015; LINN, 2018; ALLAN, 2019) e acadêmicos (GORDON, 1978; TIFFIN, 1999; GERAGHTY, 2005). Ainda que o termo mitologia seja usado como estratégia de marketing ou sem o seu sentido forte, o emprego da palavra motiva uma indagação sobre o que tem caracterizado os imaginários mitológicos, desde os tempos arcaicos até a contemporaneidade.

A partir das características das mitologias ancestrais e usando o conjunto de narrativas que compõem o imaginário de Guerra nas Estrelas como exemplo de uma mitologia contemporânea, propõe-se aqui um estudo comparativo sobre o que as aproxima e as distancia, a partir da análise de suas características.

Para tanto, com o objetivo de se estabelecer uma noção de mito e mitologia aplicável a este estudo, desenvolve-se na primeira parte do artigo uma revisão sobre esses conceitos nos pensamentos de Mircea Eliade (1972, 1992), Ernst Cassirer (1977, 1992), Carl Jung (2014) e Gilbert Durand (1985, 2002, 2004).

Estabelecidas essas noções, a segunda parte analisa quais características que definem o mito e de que forma elas estão presentes em Guerra nas Estrelas, apontando as aproximações e distanciamentos existentes entre a mitologia ancestral e a chamada mitologia contemporânea.

\section{Revisão do conceito de mito}

Mitologias são conjuntos de mitos relacionados a um determinado grupo social, religião ou cultura que compartilhe as mesmas crenças. Assim, para falarmos de mitologia, é preciso revisitarmos a ideia de mito. Mircea Eliade (1972, p. 9) afirma que "o mito é uma realidade cultural extremamente complexa, que pode ser abordada e interpretada através de perspectivas múltiplas e complementares".

O conceito de mito recebeu diferentes definições na antropologia, religião, filosofia, etnografia, sociologia e psicanálise. Ao longo dos séculos XIX e XX, há uma transformação nas teorias que o abordam, o que resulta em compreensões radicalmente diferentes sobre sua origem e função. De forma 
geral, enquanto predomina nas teorias do século XIX a visão do mito como forma de conhecimento primitiva e inferior - quando comparada com a da ciência moderna -, no século XX, prevalece a ideia de que os mitos não são uma forma de conhecimento inferior à ciência, mas sim algo que a antecede e que exerce outras funções. Tal mudança é acompanhada também por um processo de remitologização do mundo, segundo Gilbert Durand (2004), expresso principalmente nas artes, na psicanálise e na religião, revertendo um longo processo de quase dois milênios de desvalorização do mito.

Claude Lévi-Strauss (2012) é um dos críticos da visão do mito como algo inferior ou primitivo. Ele ressalta a capacidade dos povos arcaicos (ou ágrafos) de possuir um pensamento desinteressado - isto é, que transcenda às exigências imediatas de sobrevivência — , sendo movidos pela necessidade ou desejo de compreender o mundo que os circunda, tanto o natural como o social, e fazê-lo por meios intelectuais, assim como um filósofo ou um cientista (LÉVI-STRAUSS, 2012, p. 39). Ele afirma que, apesar de empregar um modo intelectual e com capacidade mental similar ao do científico, o pensamento mítico difere deste à medida que o mito tem a pretensão de alcançar uma compreensão total do universo, e pelo fato do pensamento mítico ser mais abastecido com um tipo de percepção do mundo, que é diferente da que o homem moderno necessita (LÉVI-STRAUSS, 2012, p. 41-43).

A ideia de que o pensamento mítico é algo diferente e não inferior à ciência está presente também na visão de Ernst Cassirer (1977, 1992). Para ele, o mito é uma forma simbólica, assim como a linguagem, a arte e a ciência. Cada uma delas tendo um papel específico na relação do ser humano com o mundo e todas cooperando para um fim comum: o do "processo de auto libertação progressiva do homem" (CASSIRER, 1977, p. 357). Cassirer (ibidem, p. 123-125) crítica as tentativas de interpretação alegórica e as formas modernas de explicação dos fenômenos míticos, que resultam na negação deles. O mito deve, para o filósofo, ser entendido a partir da perspectiva das sociedades arcaicas que o elaboraram, não como um faz de conta e sim como uma crença: “Embora o mito seja fictício, é uma ficção inconsciente; a mente primitiva não tinha consciência do sentido das próprias criações" (ibidem, p. 124).

Cassirer também estabelece a conexão do mito com o processo de criação artística, ressalvando, fundamentado na perspectiva kantiana, que mito e arte se diferenciam: a arte não tem compromissos com a realidade, é indiferente à existência ou não de seu objeto, enquanto o fenômeno mítico 
baseia-se no empírico, na crença da realidade de seu objeto (ibidem, p. 125126). E a construção poética que o mito faz dessa realidade na qual ele crê caracteriza-se por ser dramática:

A percepção mítica está sempre impregnada destas
qualidades emocionais: o que se vê ou se sente é cercado de
uma atmosfera especial - de alegria ou tristeza, angústia,
excitação, exultação ou depressão. E não podemos falar
de "coisas" como de matéria morta ou indiferente. Todos
os objetos são benignos ou malignos, amigos ou inimigos,
familiares ou sobrenaturais, encantadores e fascinantes
ou repelentes e ameaçadores (ibidem, p. 128).

Mircea Eliade (1972, p. 9) afirma que o mito trata sempre de uma história sagrada ocorrida em tempos primordiais, no princípio de tudo. Essas narrativas são o resultado da ação de seres sobrenaturais que deram origem a algo, seja uma realidade total como o Cosmos, seja um fragmento da realidade como uma ilha, um comportamento humano, uma instituição ou uma planta: “É sempre, portanto, a narrativa de uma 'criação': ele relata de que modo algo foi produzido ou começou a ser. O mito fala apenas do que ocorreu, do que se manifestou plenamente" (ibidem).

Para Eliade, os mitos estabelecem a relação do ser humano com o sagrado e as manifestações deste no mundo, sendo assim histórias verdadeiras, pois referem-se à realidade que vivenciamos empiricamente: "O mito cosmogônico é 'verdadeiro' porque a existência do Mundo está aí para prová-lo; o mito da origem da morte é igualmente 'verdadeiro' porque é provado pela mortalidade do homem, e assim por diante" (ibidem).

A função principal do mito, segundo Eliade (ibidem), é a de estabelecer os modelos de comportamento para os seres humanos no mundo. Eles fornecem os modelos exemplares, os paradigmas para as sociedades arcaicas. Tais paradigmas foram praticados in illo tempore, nos tempos míticos, quando gestos como o matrimônio, o funeral e a caça foram realizados originalmente. Para essas sociedades, os tempos míticos antecedem o tempo histórico, sendo os rituais uma imitação e uma repetição dos acontecimentos primordiais.

Outra função do mito, destacada por Cassirer (ibidem, p. 136-138), é que ele, assim como a religião, é uma negação enfática da possibilidade da morte. Essa função se evidencia nas narrativas que enfatizam o sentimento de unidade indestrutível da vida, sendo que a existência de cada ser não tem 
limites definidos no espaço e no tempo - prevalecem aqui as ideias do tempo cíclico, e de um culto aos antepassados e às suas tradições, o que alimenta a característica conservadora dos mitos.

Eliade também enfatiza a importância do conceito cíclico do tempo no mito, explicitado pelos rituais que buscam reviver o sagrado que acontecia in illo tempore. A esse processo de repetição cíclica do que aconteceu em tempos míticos ele denomina como eterno retorno:

Tudo começa de novo, no princípio, a cada instante. O passado nada mais é do que uma prefiguração do futuro. Nenhum acontecimento é irreversível, e nenhuma transformação é final. Num certo sentido, é até possível dizer que nada de novo acontece no mundo, pois tudo não passa de uma repetição dos mesmos arquétipos primordiais; esta repetição, ao atualizar o momento mítico em que o gesto arquetípico foi revelado, mantém constantemente o mundo no mesmo instante inaugural do princípio. O tempo só torna possível o aparecimento e a existência das coisas (ELIADE, 1992, p. 87).

A partir da perspectiva da psicologia analítica, Carl Gustav Jung vê o mito como uma forma de atender a uma profunda necessidade psíquica do ser humano que procura pela projeção e pela exteriorização dos próprios conteúdos psíquicos inconscientes, espelhando-os nas coisas dos mundos natural e social, apreender os significados dos fenômenos. Jung pensa o mito como uma manifestação dos arquétipos, definidos por ele como imagens primordiais, universais e atemporais (JUNG, 2014). Ele entende que todos os arquétipos dos quais surgiram os mitos encontram-se no inconsciente - mais especificamente, no que ele denominou de inconsciente coletivo, que se distingue do inconsciente pessoal - , sendo o inconsciente "um sujeito atuante e padecente, cujo drama o homem primitivo encontra analogicamente em todos os fenômenos grandes e pequenos da natureza" (ibidem, p. 15). Nesse processo, o inconsciente assemelha os acontecimentos psíquicos (anímicos) às experiências externas sensoriais:

Para o primitivo não basta ver o Sol nascer e declinar; esta observação exterior deve corresponder - para ele - a um acontecimento anímico; isto é, o Sol deve representar em sua trajetória o destino de um deus ou herói que, no fundo, habita unicamente a alma do homem (ibidem, p. 14) 
Assim, para Jung (2014, p. 155), "a mentalidade primitiva não inventa mitos, mas os vivencia". Eles têm um significado vital para as sociedades arcaicas e quando ocorre a perda da herança mítica o resultado é degeneração e desaparecimento dessas sociedades: "a mitologia de uma tribo é sua religião viva, cuja perda é tal como para o homem civilizado, sempre e, em toda parte, uma catástrofe moral" (ibidem, p. 156).

Tendo como ponto de partida o pensamento junguiano, Gilbert Durand (2002, p. 63) entende que o mito é uma narrativa, resultado de um esboço de racionalização dos arquétipos transformados em ideias e dos símbolos transformados em palavras. Ele amplia o sentido etnográfico e antropológico do conceito, entendendo o mito como "um sistema dinâmico de símbolos, arquétipos e esquemas', sistema dinâmico que, sob o impulso de um esquema tende a compor-se em narrativa" (DURAND, 2002, p. 62-63). Durand (1985, p. 245) afirma que o pensamento mítico é aplicado preferencialmente às grandes indagações que a ciência não tem sido capaz de responder.

A partir das reflexões desses pensadores, que apresentam uma visão alinhada à revalorização do mito e de sua importância para o ser humano em qualquer época, podemos sintetizar que o mito pode ser definido²:

i. quanto à sua forma: narrativa ficcional dramática;

ii. quanto ao tema: relata predominantemente a criação de algo (o Universo, uma cidade, um ser, uma planta, um sentimento, uma emoção, uma qualidade, um comportamento, etc.) acontecida in illo tempore, isto é, nos tempos míticos que antecedem o tempo histórico, e protagonizada por entes sobrenaturais;

iii. quanto à sua função psicológica: dar sentido ao Cosmos e às coisas nele existentes, principalmente dar significado à existência dos seres humanos, a partir de uma narrativa totalizante que busca responder especialmente a questões ontológicas, fontes das angústias essenciais humanas;

\footnotetext{
1 Em sua tese sobre o trajeto antropológico do imaginário, Durand chama de esquema a junção figurativa no âmbito psíquico entre os gestos inconscientes de sensório-motricidade (os reflexos postural, digestivo e sexual) e as representações criadas pelo ser humano (imagens simbólicas ou arquetípicas), sendo os esquemas o esqueleto dinâmico da imaginação (DURAND, 2002, p. 60)

2 Ressaltamos que se busca nessa síntese uma conceituação de mito com o objetivo de aplicá-la na análise desenvolvida neste artigo, sem a pretensão de esgotar o tema.
} 
iv. quanto à sua função social: estabelecer os modelos exemplares de comportamento para as sociedades, funcionando como uma religião cívica;

v. quanto à sua universalidade: por ser uma manifestação racional dos arquétipos, o discurso mítico constitui-se em uma linguagem universal e atemporal;

vi. quanto à crença: ainda que seja produto da imaginação humana (muitas vezes de forma inconsciente), o mito é investido de uma crença, tratando-se, portanto, de uma narrativa sagrada que remete a uma realidade do mundo.

Essas seis características (forma, tema, função psicológica, função social, universalidade e crença) serão utilizadas como parâmetro para a análise que é feita mais à frente sobre a saga Guerra nas Estrelas.

\section{Contexto da criação dos mitos ancestrais}

Para analisar a pertinência da ideia de mitologia contemporânea, além de recorrer àquelas que são as principais características definidoras do mito, é importante também entender elementos do processo criativo, que produziu as mitologias ancestrais, e em quais contextos essas criações ocorreram.

Os mitos surgem a partir da capacidade inventiva da imaginação do homo sapiens sapiens de criar coisas que não existem no mundo natural, impulsionada, em última instância, pelas angústias existenciais provocadas pela autoconsciência da finitude e do tempo. As narrativas míticas são, assim, a resposta da imaginação e da razão para elementos desconhecidos e ameaçadores do mundo, além de questões ontológicas que afligem o ser humano. Embora investigações arqueológicas tragam indícios de atitudes ritualísticas do homo neanderthalensis de enterrar seus mortos, e consequentemente ter consciência da morte e refletir sobre ela de uma forma que outras criaturas não conseguem, as evidências arqueológicas e antropológicas, atualmente mais sólidas, apontam para o homo sapiens sapiens como o primeiro a desenvolver as capacidades de abstração e de pensamento simbólico capazes de gerar narrativas míticas e os ritos delas derivados.

Os primeiros mitos nascem provavelmente no período Paleolítico, produto da imaginação dos povos caçadores-coletores, e desde seu desenvolvimento

3 A ideia do mito como religião cívica é desenvolvida por Jean-Pierre Vernant na obra Mito e religião na Grécia Antiga (2006). 
inicial buscam não se ater apenas ao sobrenatural, mas também conectaremse ao mundo real (ARMSTRONG, 2006). O mito busca assim uma conexão entre o sagrado (aquilo que transcende o mundo natural) e o profano (aquilo que faz parte da vida cotidiana), possibilitando aos caçadores-coletores, por exemplo, lidar com as emoções decorrentes do ato de matar animais.

Armstrong (2006) propõe em sua análise da história do mito que há uma progressiva mudança em como o ser humano sente e se relaciona com os mitos, desde o tempo dos caçadores-coletores até o da constituição das cidades e da vida urbana. Segundo ela, há um paulatino distanciamento na conexão entre o sagrado e o profano, tornando-se o mito cada vez mais abstrato e afastado do cotidiano. Esse afastamento, no entanto, não significa a exclusão dos mitos da vida do homem. Pelo contrário, a importância dos mitos permanece no mundo contemporâneo. A necessidade humana por eles é empiricamente confirmada pelo impacto e alcance das narrativas míticas das grandes religiões nos tempos atuais, além da contínua influência que os mitos ancestrais exercem no campo da criação artística.

Eliade $(1972,1992)$, Campbell $(1959,1997)$ e Jung (2014) são alguns dos pensadores que defendem a ideia da permanente influência dos mitos ancestrais na produção simbólica humana. Durand (2004, p. 20) também afirma que há uma constante atualização dos mitos ancestrais, fenômeno esse recorrente no processo de criação de narrativas. O pensador francês vai ainda além ao afirmar que não há mitos novos, estando os mesmos mitos ancestrais em permanente circulação nos imaginários das sociedades com suas reaparições ocorrendo quando os criadores das narrativas, conscientemente ou não, reencontram mitos já estabelecidos (DURAND, 2004).

Os mitos são criações de indivíduos dotados de imaginação excepcional. Campbell (1959, p. 242-243) entende que o processo criativo dos mitos pode ser comandado por artistas, poetas e filósofos, como nas mitologias grega e celta-germânica, ou por pregadores, sacerdotes e profetas, como na mitologia cristã ${ }^{4}$ e outras do Oriente.

4 Embora as instituições cristãs não considerem o Cristianismo uma mitologia, à medida que adotam o conceito de mito como algo falso ou irreal, as narrativas que compõem o Antigo e Novo Testamento trazem todas as características dos mitos, como veremos adiante. Com a ressalva de que parte importante dela - a vida de Jesus Cristo - se dá no tempo linear histórico e não no tempo circular mítico (in illo tempore). Apesar dessa originalidade do Cristianismo, Eliade (1972, p. 119) entende que os eventos da Encarnação, Ressurreição e Ascensão mostram que o drama de Jesus transcende a História e que para obter a salvação os que creem nessa narrativa adotaram a repetição ritual desse modelo exemplar de vida e dos seus ensinamentos, características essas essenciais dos mitos. 
A criação dos mitos arcaicos se deu, geralmente, quando inserida num processo coletivo e anônimo, sendo as narrativas míticas ancestrais construídas e transmitidas ao longo de séculos por meio da tradição oral. Em algumas sociedades, como na Grécia clássica, conforme destaca Vernant (2006, p. 17), deve-se ressaltar a contribuição, no âmbito familiar e privado, de mães, avós e amas de leite na transmissão e consolidação dessas narrativas. Em outras sociedades, no entanto, os mitos não são recitados por sacerdotes diante dos não-iniciados, como mulheres e crianças, ou só podem ser recitados durante a noite e em certa época do ano (ELIADE, 1972).

Vários dos contadores de estórias anônimos contribuíram também na modificação dos conteúdos míticos, o que dá ao mito na tradição oral o dinamismo de se atualizar ante às transformações socioculturais da sociedade na qual se insere. Isso, no entanto, ocorre dentro de certos limites. Ao analisar a mitologia grega, Vernant (2006, p. 25) destaca que o processo criativo dos mitos que a compõem obedece a limitações rigorosas impostas pela coletividade e por suas tradições. Ele afirma que um autor não pode modificar as narrativas míticas ao seu bel-prazer. Isso, no entanto, não impede o surgimento de diferentes versões para um mesmo mito, algumas até mesmo incongruentes, especialmente quando tratamos de mitologias relacionadas a sociedades maiores e mais complexas, como a greco-romana, ou a grandes religiões, como a cristã.

Outro fator importante no processo de criação dos mitos é que essas estórias se transformaram e se enriqueceram graças também à influência e à troca com outras culturas (ELIADE, 1972, p. 7), fazendo das narrativas míticas uma espécie de work in progress permanente no período que antecede à escrita.

O advento da escrita, no entanto, leva as sociedades, como a da Grécia antiga, à fixação desses conjuntos de narrativas por supostamente um único autor, como Homero e Hesíodo, levando à perda do dinamismo da natureza original dos mitos. Para Brandão (1986, p. 25), "a forma escrita desfigura o mito de algumas de suas características básicas, como, por exemplo, de suas variantes, que se constituem no verdadeiro pulmão da mitologia".

Assim, uma consequência importante da escrita é que ela leva à busca de conformidade e consequente constituição de cânones no universo mitológico. A conformidade visa a manter a harmonia dos universos ficcionais, levando a uma eliminação de eventuais contradições entre as diferentes versões de um mesmo mito, que disputam qual conta a estória verdadeira sobre ele. 
O resultado é o estabelecimento de um conjunto de narrativas canônicas, que levam ao enrijecimento do mito e à perda de vitalidade orgânica.

Exemplo de como se dá essa busca de conformidade e constituição do cânone vem do problema da divindade de Jesus na mitologia cristã. Ehrman (2014) indica que pelo menos duas questões centrais emergem dos primeiros textos que compõem a mitologia cristã: se Jesus já nasce como uma divindade ou torna-se divino durante sua vida terrena e como, no monoteísmo cristão, conciliar a ideia da existência de duas divindades (Jesus e Deus).

A construção da mitologia cristã, embora repleta de contribuições de uma fase de tradição oral, se dá já na era da escrita, o que reduz a dinâmica dos mitos, mas não impede, dada a sua característica orgânica, o surgimento de visões distintas sobre o mesmo fenômeno. Assim, há nos primeiros escritos cristãos quatro versões sobre o momento em que Jesus torna-se o filho de Deus: na ressurreição, segundo a tradição oral; no batismo, segundo o evangelho de Marcos; no nascimento (ou na concepção entre o Espírito Santo e Maria), segundo os evangelhos de Lucas e Mateus; e antes mesmo da criação, segundo o evangelho de João. Para Ehrman (2014), essas versões mostram duas visões: uma é a de que Jesus nasce na condição de um ser humano e sua exaltação, sua elevação à condição divina, se dá no seu batismo ou por ocasião da sua ressurreição5; outra é a de que ele é uma divindade por natureza, antes mesmo do nascimento, sendo feito da mesma essência de Deus. As visões sobre a natureza divina de Jesus são um exemplo de como diferentes versões são criadas ao longo do processo de construção dos mitos.

Qualquer que fosse a visão a prevalecer sobre o momento da divindade de Jesus no cânone do cristianismo, outro problema emergia: a da existência de duas divindades (Jesus e Deus) no panteão de uma religião monoteísta. Da mesma forma, surgiram várias versões para conciliar essa incongruência. Ehrman (2014, sem paginação) analisa essas diferentes perspectivas mostrando que elas eram internamente inconsistentes e contraditórias. 
Ambas as questões - da origem da divindade em Jesus e da existência de duas divindades em uma religião monoteísta - começam a ser resolvidas no momento em que a Igreja faz a grande consolidação do cânone cristão no primeiro Concílio de Niceia, no ano 325, que introduz a doutrina da Santíssima Trindade.

Assim, para a consolidação do cânone, além da escrita, há a necessidade de uma centralização, organização e conformação do conjunto de mitos por um autor ou instituição ${ }^{6}$. Foi o que aconteceu com a mitologia cristã, cujas narrativas foram administradas pela Igreja em Roma, a partir do século IV, e com a mitologia grega, que teve seus mitos fixados pelas obras poéticas atribuídas a Homero e Hesíodo, entre os séculos 10 e 7 antes de Cristo, e na obra Biblioteca mitológica, atribuída a Apolodoro e provavelmente escrita entre os séculos 1 e 2 .

A consolidação da mitologia grega se dá, segundo Eliade (1972, p. 111), com a predominância do documento escrito sobre a tradição oral e a experiência vivida. O resultado é que as obras gregas de Homero e Hesíodo, para Eliade (ibidem), nutrem a cultura ocidental com um universo religioso dessacralizado e uma mitologia desmitificada. Assim, a consolidação do cânone, no caso da mitologia grega, representa o triunfo de uma visão artística sobre a experiência religiosa.

Dessa forma, o processo de criação das narrativas míticas precisa ser entendido também no âmbito da relação de mão dupla entre mitologia e arte, embora elas se constituam como formas simbólicas distintas, já que a arte, conforme vimos na perspectiva de Cassirer $(1977,1992)$, não tem compromisso algum com a realidade, enquanto a mitologia baseia-se na crença de que o seu objeto é real (CASSIRER, 1977, p. 125-126) buscando dar sentido ao mundo e oferecer paradigmas de conduta na vida real a um grupo social. Essa função cívica da mitologia, geradora de cultos e rituais, faz os mitos gregos, por exemplo, transbordarem o campo da arte (literária) e adentrarem o da religião, conforme afirma Vernant (2006).

\section{Pertinência da ideia de mitologia contemporânea}

Com o objetivo de examinar a pertinência da ideia de mitologia contemporânea, analisamos a seguir o universo de Guerra nas Estrelas. Tal universo

6 Mesmo com a busca de conformidade, podem restar inconsistências no mito, como ocorre na mitologia cristã, em que evangelhos que divergem sobre a origem divina de Jesus permanecem como parte do cânone. 
tem sido construído desde 1977 por meio de filmes, séries televisivas, livros, graphic novels e videogames. A penetração das narrativas globalmente e o faturamento obtido colocam o imaginário de Guerra nas Estrelas como um dos mais conhecidos na cultura popular contemporânea e um dos mais valiosos ${ }^{7}$.

Guerra nas Estrelas passou a ser propriedade da The Walt Disney Company8 em 2012 e os planos de explorar criativa e comercialmente o potencial da saga significaram manter o universo narrativo transmídia de Guerra nas Estrelas em contínuo desenvolvimento. Com os elementos centrais de seu imaginário estabelecidos, e consagrados junto à audiência, as narrativas seguem sendo criadas, seja para expandi-los, seja para esmiuçar, desvendar e conectar personagens, situações e temas presentes no seu universo principal.

Ao se constituir numa saga bem-sucedida, Guerra nas Estrelas consolidou a ideia de ser uma mitologia contemporânea, sendo assim tipificada não só por seus criadores, como também pela mídia e por estudos acadêmicos. Vejamos então, tendo como referência o que caracteriza uma mitologia ancestral, quais elementos presentes em Guerra nas Estrelas estimulam sua classificação como tal. As principais convergências entre as características da saga e as das mitologias ancestrais relacionam-se à forma, ao tema, à sua universalidade e ao processo criativo.

Em relação à forma e ao tema, Guerra nas Estrelas apresenta as mesmas características que os mitos ancestrais, ao constituir-se como um conjunto articulado de narrativas ficcionais dramáticas protagonizadas por personagens de poderes sobrenaturais. O protagonismo do sobrenatural é centrado na ideia da existência de um campo energético denominado como a força ${ }^{9}$. Em torno dela forma-se o antagonismo central representado pela luta entre o lado iluminado (o bem) e o lado negro (o mal) da força, segundo o cânone da saga (WINDHAN, 2005, p. 18).

Outra similaridade temática está no fato da narrativa se dar in illo tempore, e a questão da origem se colocar de imediato em Guerra nas Estrelas desde

7 Estudo de Aswath Damodaran (2016) estimou o valor da marca Star Wars em cerca de US\$10 bilhões, em 2015. Esse valor indica que a franquia é mais valiosa do que marcas como Rolex, Dell, Nintendo, Burger King e Lego, entre outras (FORBES, 2021).

8 Em 2020, a The Walt Disney Company foi considerada o segundo maior conglomerado de mídia do mundo em termos de faturamento (BUSINESS INSIDER, 2021). Em 2012, ela adquiriu a Lucasfilm, produtora detentora dos direitos de Guerra nas Estrelas.

9 Embora alguns fãs entendam que há uma explicação científica para a força, afirmando que ela advém de microscópicas formas de vida que estão presentes em todas as células de seres vivos chamadas de midi-chlorians - , de acordo com o cânone da saga, a força é algo que transcende os seres vivos e as midi-chlorians têm o papel de apenas se comunicarem com ela, revelando seu poder (WINDHAN, 2005, p. 18) 
o primeiro filme lançado no cinema - Uma Nova Esperança (A New Hope; dir.: George Lucas, 1977) - com a cena de abertura que traz o texto: “Há muito tempo, em uma galáxia muito, muito distante...". Além disso, os nove filmes para o cinema lançados entre 1977 e 2019 trazem as diversas origens dos principais elementos que constituem o universo de Guerra nas Estrelas: os lados iluminado e escuro da força, a República, o Império, os rebeldes, a Estrela da Morte, entre outras.

Em relação à universalidade da saga, este fator está relacionado à ideia de o mito ser uma manifestação racional dos arquétipos e, por conta disso, a narrativa mítica constituir-se em uma linguagem universal e atemporal. Neste aspecto, a saga é universal, pois ao explorar determinados arquétipos - especialmente o do herói e do seu antagonista (monstro, vilão, sombra) - de forma eficiente, Guerra nas Estrelas consegue se tornar uma narrativa cujo imaginário transcende etnias e culturas, fazendo com que indivíduos e grupos distintos compartilhem a mesma visão de mundo.

No que diz respeito ao seu processo criativo, apesar de não se tratar de um conjunto de narrativas orgânicas como as mitologias ancestrais, e ser conduzida por uma lógica de negócios, planejada e organizada por corporações de mídia e entretenimento, a criação ${ }^{10}$ de Guerra nas Estrelas também se defronta com a necessidade de busca de conformidade e consolidação de um cânone, ainda que tenha um processo criativo planejado, e casos de inconsistência em partes da narrativa aconteçam.

À medida que o universo da saga é expandido, fãs, jornalistas e críticos têm apontado contradições e imperfeições na construção dele, especialmente por conta de falhas na criação dos roteiros para os filmes de cinema e séries de TV (BARTLEET, 2017; MILLER, 2018; DI PLACIDO, 2020). No entanto, diferentemente de uma mitologia ancestral em que a busca da conformidade pode levar séculos (como vimos no exemplo da mitologia cristã), no ambiente controlado de Guerra nas Estrelas, ela pode levar apenas décadas. Foi o caso do ajuste feito pelo livro The Empire Strikes Back: From a Certain Point of View, lançado em 2020, que esclarece 40 anos depois uma inconsistência no roteiro do filme O império contra-ataca (The Empire Strikes Back, dir,: Irvin Kershner,

10 É possível falar que há similaridade também em relação à autoria coletiva, em Guerra nas Estrelas, ainda que ela se dê em condições distintas das de uma mitologia ancestral. Como se trata de uma narrativa para entretenimento inserida na lógica do mercado - sem a conotação do sagrado que as mitologias arcaicas trazem - o processo de criação em Guerra nas Estrelas é liderado por corporações que buscam maximizar lucros e minimizar riscos, regra que rege a contratação de seus roteiristas, escritores, diretores, etc. 
1980) referente a uma crucial passagem da estória: o encontro entre os personagens Yoda e Luke Skywalker (CRUMLISH, 2021).

Guerra nas Estrelas tem um proprietário, que pode ajustar seu universo por iniciativa própria, ainda que esses ajustes estejam sujeitos também a certos limites impostos pela comunidade de fãs. Nesse aspecto, a preocupação com a consolidação e harmonização da saga levou à formação em 2012 de um comitê de onze escritores denominado story group para cuidar do seu cânone (HOLT, 2017).

Embora as mitologias ancestrais e Guerra nas Estrelas tenham naturezas e formas de controle do processo de criação diferentes, o que se observa são similaridades na consolidação dos cânones em ambos os tipos de processos criativos.

Já as principais divergências entre as características da saga e as das mitologias ancestrais relacionam-se às funções psicológica e social e quanto à crença.

Ainda que se trate de uma atualização de mitos ancestrais, Guerra nas Estrelas insere-se em um contexto histórico totalmente distinto daqueles em que se inseriram as mitologias tradicionais. Dada a forma como o homem contemporâneo sente e pensa o mundo e pelo seu nível de conhecimento acumulado, incluindo o oriundo das descobertas da ciência e dos avanços tecnológicos, sua forma de interpretar os mitos diferencia-se da do homem arcaico ou do mundo antigo.

Outra diferença é que, enquanto o homem moderno tem consciência da ficcionalidade de Guerra nas Estrelas e do seu consequente descompromisso com a realidade e a verdade, o homem das sociedades arcaicas interpretava seus mitos como histórias verdadeiras, conectados a sua realidade empírica, conforme nos lembra Eliade (1972). Isso não significa que uma narrativa como Guerra nas Estrelas não corrobore visões de mundo e atitudes morais da vida real, mas isso se dá em um patamar mais abstrato e em estruturas socioculturais mais complexas.

Em parte, pelas mesmas razões, a saga cumpre de forma bastante limitada o que seriam as funções psicológicas e sociais de uma mitologia tradicional. Ainda que consideremos que constrói, a partir do dualismo entre o bem e o mal presente em vários elementos narrativos (natureza dos personagens, disputas político-ideológicas, etc.), uma ampla metáfora sobre o sentido do Cosmos e da vida e mostre modelos exemplares de comportamento, isso 
ocorre sem o mesmo alcance e impacto emocional dos mitos ancestrais, que ao fazerem isso estabeleciam uma conexão com a realidade empírica de suas sociedades, sendo interpretados como verdadeiros. A saga também não estabelece rituais e uma relação com o sagrado com impactos no comportamento cotidiano das sociedades, como faziam ou fazem as mitologias arcaicas. É preciso ressalvar que no mundo contemporâneo tais funções psicológicas e sociais desempenhadas pelas mitologias ancestrais não desapareceram. Elas têm sido exercidas, ainda que com algumas transformações, principalmente pelas grandes religiões e, de forma inalterada, pelas práticas sagradas em sociedades tribais nas quais o mito permanece vivo, em que não ocorreram processos de aculturação, dessacralização e desmitificação.

Guerra nas Estrelas também se distancia dos mitos ancestrais quanto a estar investida de uma crença, pois, supõe-se que o público que frui suas narrativas tenha plena consciência da sua ficcionalidade e de seu descompromisso com a realidade. É possível falarmos aqui no pacto que se firma entre o público e o universo canônico da narrativa, em que há uma confiança estabelecida, mas não em crença no sentido de ligação entre sagrado e profano como se estabelece nas mitologias tradicionais.

Assim, quando comparada às características essenciais do mito ancestral, observa-se que Guerra nas Estrelas apresenta convergências especialmente em relação à forma, ao tema, à universalidade e ao processo de criação. Por outro lado, em função das transformações nos contextos social e cultural, ela não apresenta as mesmas funções psicológica e social dos mitos ancestrais, assim como não é investida de uma crença como aqueles.

\section{Conclusão}

Partimos da revisão dos conceitos consolidados de mito e da contextualização do panorama histórico de criação das mitologias ancestrais para usá-los como parâmetros no estudo de caso da saga Guerra nas Estrelas, com o objetivo de verificar a pertinência da sua frequente classificação como mitologia contemporânea.

Ao final, observamos convergência entre as características das mitologias ancestrais e as de Guerra nas Estrelas em relação à forma, tema, universalidade e etapas do processo de criação, resultado talvez da permanente circulação dos mitos ancestrais nas sociedades e de sua capacidade de impactar nas 
criações de narrativas, conforme teses defendidas por Durand $(1985,2004)$, Campbell (1959, 1997) e Jung (2014), entre outros.

Por outro lado, também constatamos que Guerra nas Estrelas, como exemplo de mitologia contemporânea, não cumpre as mesmas funções sociais e psicológicas exercidas pelas mitologias ancestrais, assim como não é investida do mesmo tipo de crença que aquelas mitologias eram ou são. As diferenças advêm em parte dos contextos históricos distintos em que se inserem e em parte da forma díspar como o homem contemporâneo sente e pensa o mundo, dado o seu nível de conhecimento acumulado e sua forma distinta de interpretar os mitos ao ter consciência plena de sua ficcionalidade.

Cabe aqui ressaltar que embora se distancie de cumprir no mesmo patamar e com a mesma importância, as funções sociais e psicológicas das mitologias ancestrais, esses tipos de funções não estão ausentes em Guerra nas Estrelas. Estudos têm apontado para múltiplas interpretações da saga, quando relacionada aos cenários econômicos, políticos e comportamentais em que se insere, seja entendendo-a como discurso anticapitalista (MUSSET, 2020) ou pseudo-feminista (KOUSHIK, REED, 2018), seja como parábola da situação das democracias nos países desenvolvidos (LANCASHIRE, 2002) ou da emergência da globalização (SILVIO, 2007), entre outros. Sem entrar no mérito dessas interpretações, o que elas evidenciam é o potencial da narrativa para impactar na subjetividade contemporânea em distintos contextos políticos e econômicos, ainda que aparentemente sem o mesmo potencial das mitologias tradicionais. Abordar esse aspecto da saga, no entanto, merece um estudo específico que poderia se desenvolver a partir dos fundamentos propostos neste artigo.

Os achados iniciais aqui apontados sugerem pelo menos duas hipóteses a serem testadas em futuras investigações sobre este tema e que incluam uma amostra ampla de narrativas contemporâneas que tragam características similares a dos mitos ancestrais assim como Guerra nas Estrelas.

A primeira hipótese, baseada numa comparação rigorosa entre os conceitos estabelecidos pelos mitos ancestrais e as características das grandes narrativas contemporâneas oriundas do campo das artes, é a de que seria inadequado tipificar essas narrativas como mitologias no sentido forte do termo, a partir das características essenciais identificadas no conjunto dos mitos ancestrais. Nessa perspectiva, classificar as narrativas contemporâneas como tal não condiz com o alcance que os mitos ancestrais tiveram e têm. 
A segunda hipótese, que nos parece mais promissora, é a de que esse tipo de narrativa contemporânea pode indicar um novo estágio no longo processo de transformação dos mitos, que os vem levando às atualizações de suas funções, sem a perda de seu papel principal de oferecer ao homem respostas sobre questões que outras formas de conhecimento simbólico, como a ciência, não têm condições de responder.

Conforme foi apresentado no artigo, a relação do homem com os mitos ancestrais mudou ao longo da História - do Paleolítico à Antiguidade — tornando-se mais abstrata e distante da vida cotidiana (ou profana). Essas transformações podem ter alcançado um novo patamar na era moderna, em função dentre outros fatores da remitologização do mundo a partir do século 20 , conforme apontado por Durand (2004) após um longo período de desmitologização e de desvalorização dos mitos ancestrais. Narrativas contemporâneas, como a saga Guerra nas Estrelas, podem ser um indicador dessa atualização do mito e trazer nelas alguns dos novos elementos que o caracterizam.

Sílvio Anaz é doutor em Comunicação e Semiótica pela PUC-SP, com pós-doutorado em Meios e Processos Audiovisuais pela ECA-USP. Foi pesquisador-visitante na York University.

silvioanaz@alumni.usp.br

\section{Referências}

ALLAN, D. G. Star Wars: Revenge of the Myth. CNN. 1 mar. 2019. Disponível em: https:// edition.cnn.com/2015/05/04/opinions/allan-star-wars/index.html. Acesso em: 28 jan. 2021.

APOLODORO. Biblioteca mitológica. Madri: Editorial Gredos, 1985.

ARMSTRONG, K. A Short History of Myth. Edimburgo: Cannongate Books, 2006. E-book.

BARTLEET, L. 25 plot holes that will ruin 'Star Wars' for pedants. New Music Express. 3 jan. 2017. Disponível em: <https://www.nme.com/blogs/the-movies-blog/star-wars-plotholes-1921277>. Acesso em: 3 fev. 2021.

BRANDÃO, J. S. Mitologia grega. Volume I. Petrópolis: Vozes, 1986.

BUSINESS INSIDER. The 30 biggest media companies in the world. Disponivel em: $<$ https://www.businessinsider.in/tech/the-30-biggest-media-companies-in-the-world/ slidelist/52525061.cms>. Acesso em: 27 jan. 2021. 
CAMPBELL, J. O herói de mil faces. São Paulo: Cultrix/Pensamento, 1997. The Historical Development of Mythology. Dedalus, v. 88, n. 2, p. 232-254, 1959.

CASSIRER, E. Antropologia filosófica. São Paulo: Editora Mestre Jôu, 1977.

. Linguagem e mito. São Paulo: Perspectiva, 1992.

CRUMLISH, C. Star Wars: The Empire Strikes Back Yoda plot hole explained 40 years later. Express. 5 jan. 2021. Disponível em: <https://www.express.co.uk/entertainment/ films/1379987/star-wars-plot-hole-the-empire-strikes-back-yoda-luke-skywalker-mark-hamill-disney-plus>. Acesso em: 4 fev. 2021.

DAMODARAN, A. Intergalactic Finance: Why the Star Wars Franchise Is Worth Nearly $\$ 10$ Billion To Disney. Forbes. 6 jan. 2016. Disponível em: <https://www.forbes.com/sites/ aswathdamodaran/2016/01/06/intergalactic-finance-how-much-is-the-star-wars-franchise-worth-to-disney/?sh=26068ab71e3b>. Acesso em: 26 jan. 2021.

D'ANCONA, M. Every era needs its myth cycle. Star Wars is ours. The Guardian. 14 dez. 2015. Disponível em: <https://www.theguardian.com/commentisfree/2015/dec/14/myth-star-wars-force-awakens-heroic-legends>. Acesso em: 28 jan. 2021.

DI PLACIDO, D. Months After Release, 'The Rise Of Skywalker' Is Still Trying To Fix Its Plot Holes. Forbes. 19 fev. 2020. Disponível em: <https://www.forbes.com/sites/ danidiplacido/2020/02/19/months-after-release-the-rise-of-skywalker-is-still-trying-to-fix-its-plot-holes/?sh=281890a673f0>. Acesso em: 3 fev. 2021.

DISNEY. Disney Gallery: Star Wars: The Mandalorian. Temporada 1. Episódio 2. Streaming (DisneyPlus). 2020.

DURAND, G. O retorno do mito: introdução à metodologia: mitos e sociedade. Revista Famecos, n. 23, abr. 2004.

. As estruturas antropológicas do imaginário. São Paulo: Martins Fontes, 2002. Sobre a exploração do imaginário: seu vocabulário, métodos e aplicações transdisciplinares. Revista da Faculdade de Educação, vol. 11, n.1/2, p. 243-273, 1985.

ELIADE, M. Mito e realidade. São Paulo: Perspectiva, 1972.

O mito do eterno retorno. São Paulo: Mercuryo, 1992.

EHRMAN, B. How Jesus Became God. São Francisco (EUA): HarperOne, 2014. E-book.

FORBES. The World's Most Valuable Brands. Forbes. 2021. Disponível em: <https://www. forbes.com/the-worlds-most-valuable-brands/\#2f3bd61119c0>. Acesso em: 26 jan. 2021.

GORDON, A. Star Wars: A Myth for Our Time. Literature-Film Quarterly, v. 6, n. 4, p. 314-326, 1978. 
GERAGHTY, L. Creating and Comparing Myth in Twentieth-Century Science Fiction: "Star Trek" and "Star Wars". Literature-Film Quarterly, vol. 33, n. 3, p. 191-200, 2005.

HOLT, N. The Women Who Run the 'Star Wars' Universe. The New York Times. 22 dez. 2017. Disponível em: <https://www.nytimes.com/2017/12/22/movies/star-wars-last-jedi-women-run-universe.html>. Acesso em: 8 fev. 2021.

JUNG, C. G. Os arquétipos e o inconsciente coletivo. Petrópolis: Vozes, 2014.

KOUSHIK, H.; REED, A. Star Wars: The Last Jedi, Beauty and the Beast, and Disney's Commodification of Feminism: A Political Economic Analysis. Social Sciences, v. 11, n, 7, nov. 2018.

LANCASHIRE, A. Attack of the Clones and the Politics of Star Wars. Dalhousie Review, vb. 82, n. 2, 2002.

LÉVI-STRAUSS, C. Mito y significado. Madri: Alianza Editorial, 2012.

LINN, W. Joseph Campbell Is the Hidden Link Between '2001,' 'Star Wars,' and 'Mad Max: Fury Road'. IndieWire. 12 mar. 2018. Disponível em: <https://www.indiewire.com/2018/03/ joseph-campbell-heros-journey-2001-star-wars-1201937470/>. Acesso em: 28 jan. 2021.

MILLER, M. A Comprehensive List of Star Wars Plot Holes. Esquire. 19 jan. 2018. Disponível em: <https://www.esquire.com/entertainment/movies/a15336898/all-star-wars-movies-plot-holes/>. Acesso em; 3 fev. 2021.

MOYERS, B.; LUCAS, G.. Of Myth and Men. Time. 18 abr. 1999. Disponível em: <http:// content.time.com/time/magazine/article/0,9171,23298,00.html>. Acesso em: 29 jan. 2021.

MUSSET, A. Star Wars: ¿una saga anti-capitalista? Universum, v. 35, n. 1, 2020.

SILVIO, C. The Star Wars Trilogies and Global Capitalism. In: SILVIO, Carl; VINCI, Tony M. (Ed.). Culture, Identities, and Technology in Star Wars Films. Londres: McFarland and Company, 2007.

TIFFIN, J. Digitally remythicised: Star Wars, modern popular mythology, and Madam and Eve. Journal of Literary Studies, vol. 15, n. 1-2, p. 66-80, 1999.

VERNANT, J.-P. Mito e religião na Grécia Antiga. São Paulo: Martins Fontes, 2006.

WINDHAN, R. Star Wars - The Ultimate Visual Guide. Nova York: DK Publishing, 2005.

Artigo recebido em 20/02/2021 e aprovado em 12/08/2021. 